\title{
Characterization of Keratocalmin, a Calmodulin-binding Protein from Human Epidermis
}

Janet A. Fairley, Glynis A. Scott, Karen D. Jensen, Lowell A. Goldsmith, and Luis A. Diaz

Department of Dermatology, Medical College of Wisconsin, Milwaukee, Wisconsin 53226; Zablocki Veterans Administration

Medical Center, Milwaukee, Wisconsin 53295; and Departments of Dermatology and Pathology,

The University of Rochester, Rochester, New York 14642

\begin{abstract}
Using affinity-purified calmodulin-binding proteins from human epidermis we have developed a monoclonal IgM antibody, ROC 129.1, to a human desmosomal calmodulin-binding protein. This antibody reacts with a submembranous $250-\mathrm{kD}$ protein from human keratinocytes and stains human epidermis in a "cell-surface pattern". Permeability studies indicated that the epitope with which this monoclonal reacts is on the inner surface of the cell membrane. Immunoelectronmicroscopy localized the antigen to the desmosome. The epitope is restricted to stratified squamous epithelia and arises between 8-12 wk of fetal development. This desmosomal calmodulin-binding protein, which we have termed keratocalmin, may be involved in the calcium-regulated assembly of desmosomes. (J. Clin. Invest. 1991. 88:315-322.) Key words: calcium • calmodulin • epidermis • desmosome
\end{abstract}

\section{Introduction}

Calcium has a profound effect on the physiology of keratinocytes in vitro. When keratinocytes are grown in low calcium conditions $(0.01-0.09 \mathrm{mM})$ the cells proliferate rapidly, do not stratify, and fail to fully differentiate (1-3). When calcium is restored to levels greater than $0.1 \mathrm{mM}$ the proliferative rate slows, the cells stratify and begin to express a number of markers of terminal differentiation (1-3). The triggering of terminal differentiation is a complex process that involves activation of phosphotidyl inositol turnover, protein kinase $\mathrm{C}$, and other calcium-dependent enzymes such as transglutaminase (4-7). The development of cross-linked cell envelopes and formation of the stratum corneum are the end results of terminal differentiation in vivo.

Many of the effects of calcium are modulated by the calcium-binding protein calmodulin. Calmodulin binds four calcium ions and, when bound, a configurational change exposes the central helical region of the protein which may then interact with a number of calmodulin-binding proteins (8-10). A role for calmodulin has been indicated in hemidesmosome formation of corneal epithelium (11), however its role in desmosome formation is unclear. In an attempt to identify the molecular events by which calcium modulates desmosome assembly

Address correspondence and reprint requests to Dr. Janet A. Fairley, 8701 Watertown Plank Road, 4072 MACC Fund Building, Milwaukee, WI 53226.

Received for publication 8 August 1990 and in revised form 28 January 1991

J. Clin. Invest.

(C) The American Society for Clinical Investigation, Inc. 0021-9738/91/07/0315/08 \$2.00

Volume 88, July 1991, 315-322 and terminal differentiation we are characterizing epidermal calmodulin-binding proteins. In this paper we report the characterization of a high molecular weight human calmodulinbinding protein that immunolocalizes to the desmosome.

\section{Methods}

Extraction and partial purification of calmodulin-binding proteins. Human neonatal foreskin was obtained from circumcisions. The epidermis was separated from the dermis by heat treatment at $56^{\circ} \mathrm{C}$ for $45 \mathrm{~s}$ and was homogenized in a $50 \mathrm{mM}$ Tris buffer, $3 \mathrm{mM} \mathrm{MgSO}, 1 \mathrm{mM}$ dithiothreitol, $0.1 \mathrm{mM} \mathrm{CaCl}$. Epidermal calmodulin-binding proteins were purified by affinity chromatography using a calmodulin affinity column (Bio-Rad, Richmond, CA) equilibrated with Tris buffer with 1 $\mathrm{mM}$ calcium as described by Wallace (12). The epidermal extract was applied to the column and the calmodulin-binding proteins were eluted with the same buffer containing $1 \mathrm{mM}$ EGTA instead of $\mathrm{CaCl}_{2}$. 2 - $\mathrm{ml}$ fractions were collected. The $\mathrm{OD}_{280}$ was measured and the ability to bind biotinylated calmodulin was tested in individual fractions by dot blot analysis.

Detection of calmodulin-binding proteins. Biotinylated calmodulin (bio-CaM) ${ }^{1}$ was used to detect calmodulin-binding proteins immobilized on a nitrocellulose membrane after separation by SDS-PAGE or directly by dot blotting. Bio-CaM was prepared according to the methods of Billingsley (13). Briefly, purified human erythrocyte calmodulin (Calbiochem Corp., La Jolla, CA) was biotinylated using biotin succinimide ester (Calbiochem) dissolved in $N, N$-dimethylformamide in the presence of $1 \mathrm{mM}$ calcium and incubated for $2 \mathrm{~h}$ at $4^{\circ} \mathrm{C}$. The resulting biotinylated calmodulin was dialyzed against $50 \mathrm{mM}$ Tris- $\mathrm{HCl}, \mathrm{pH} 7.4$, $150 \mathrm{mM} \mathrm{NaCl}, 1 \mathrm{mM} \mathrm{CaCl}_{2}$, and aliquots stored at $-20^{\circ} \mathrm{C}$. Proteins bound to nitrocellulose strips were blocked in $5 \%$ nonfat dried milk, then incubated in $10 \mu \mathrm{g}$ of bio-CaM for $30 \mathrm{~min}$. An avidin-alkaline phosphatase detection system (Vector Laboratories, Burlingame, CA) was used to detect proteins that had bound the bio-CaM. Control blots contained $5 \mathrm{mM}$ EGTA in the calmodulin buffers.

Generation of monoclonal antibodies against calmodulin-binding proteins. $10 \mu \mathrm{g}$ of the calmodulin-binding proteins were emulsified in complete Freund's adjuvant and used to immunize female BALB/c mice. Booster injections were given every 2 wk with the antigen in incomplete Freund's adjuvant. The mice were sacrificed $2 \mathrm{~d}$ after the final injection. The mouse splenocytes were fused with an NS-1 mouse myeloma cell line using PEG 1500 essentially according to the method of Kohler and Milstein (14). Hybridomas were selected by addition of hypoxanthine, aminopterine, and thymidine to the medium. Hybridoma supernatants were screened for antibody production by a sandwich ELISA using the affinity-purified calmodulin-binding proteins immobilized on microtiter wells. The hybridomas, which reacted specifically with the calmodulin-binding proteins, were cloned by limiting dilution. Antibody isotyping was performed using a subisotyping kit (Hyclone Laboratories, Logan, UT). Ascites was produced by injection of $3 \times 10^{6}$ hybridoma cells into the peritoneal cavity of pristane-primed BALB/c mice.

1. Abbreviations used in this paper: bio-CaM, biotinylated calmodulin; BMZ, basement membrane zone; IF, immunofluorescence; PF, pemphigus foliaceus. 
SDS polyacrylamide gel electrophoresis, isoelectric focusing, and immunoblotting. Keratome harvested human epidermis was extracted in $0.06 \mathrm{M}$ Tris, $2 \%$ SDS, $5 \% \beta$ mercaptoethanol, $1 \mathrm{mM}$ DTT, $1 \mathrm{mM}$ EGTA, pH 6.8, plus 0.1 mM PMSF. The extracted proteins were separated by $7.5 \%$ SDS PAGE and electrophoretically transferred to nitrocellulose for immunoblot analysis $(15,16)$. Similarly, two-dimensional analysis of samples was performed according to O'Farrell (17), using isoelectric focusing for the first dimension followed by SDS-PAGE and electrotransfer. The nitrocellulose sheets were blocked in 4\% BSA and then reacted with ROC 129.1 ascites 1:1000 in BSA, followed by an ${ }^{125}$ I-labeled anti-mouse IgM, $\mu$ chain specific (Zymed Labs Inc., San Francisco, CA). Radioactive protein bands were detected by autoradiography.

Additional proteins tested. A bovine desmosome preparation was the generous gift of Pamela Cowin, Ph.D. (Department of Dermatology, New York University). Purified spectrin was obtained from Sigma Chemical Co. (St. Louis, MO). Calmodulin was obtained from Calbiochem Corp. $10 \mu \mathrm{g}$ of each was run on SDS-PAGE and electrophoretically transferred to nitrocellulose to test the specificity of the ROC 129.1 monoclonal antibody by immunoblotting procedures.

Immunological specificity of a monoclonal antibody by immunofluo rescence and immunocytochemistry. Human skin from adult, neonatal, and fetal samples was tested for reactivity with ROC 129.1 by indirect immunofluorescence (IF). The skin was fixed in 95\% ethanol/5\% glacial acetic acid, embedded in paraffin, and cut in $4-\mu \mathrm{m}$ sections. 8 , 12,14 , and 16 wk fetal skin specimens were the gift of Dr. A. T. Lane (Department of Dermatology, Stanford University). Cryosections of the tissues were incubated with ROC 129.1 culture supernatant or ascites as the primary antibody followed by fluorescein-conjugated goat anti-IgM ( $\mu$ chain specific) as a secondary antibody. NS-1 supernatant and PBS were used as controls.

The species specificity of the ROC 129.1 monoclonal antibody was tested by indirect IF using epithelial tissues from a variety of mammalian species. They included bovine tongue epithelium, neonatal mouse skin, and monkey skin.

Human mucosal and other epithelial tissues were also tested for reactivity with the ROC 129.1 monoclonal antibody by immunoperoxidase procedures. Briefly, $5-\mu \mathrm{m}$ sections of formalin-fixed, paraffin-embedded tissue were incubated for 30 min with a 1:100 dilution of ROC 129.1 followed by a biotinylated secondary antibody and an avidinbiotin-peroxidase complex. The enzyme reaction product was developed by a final incubation of the sections in amino-ethyl-carbazole (AEC) with $0.03 \%$ hydrogen peroxide. Sections treated with normal mouse serum were included as negative controls.

Biopsies from dermatologic disorders. Skin biopsy specimens of patients with pemphigus vulgaris $(n=2)$, pemphigus foliaceus $(n=4)$, and bullous pemphigoid $(n=1)$ were fixed in formalin and embedded in paraffin. Sections were cut from these blocks and tested with ROC 129.1 monoclonal antibody by the immunoperoxidase method as previously described.

Immunolocalization of epitopes recognized by the monoclonal antibody by light microscopy. Skin organ cultures were used to determine if the epitope with which the monoclonal antibody reacted was intra- or extracellular. 2-mm pieces of human foreskin were incubated with ROC 129.1 monoclonal antibodies diluted 1:100 in keratinocyte growth medium (KGM; Clonetics Corp., La Jolla, CA) containing $0.1 \%$ saponin. Control viable foreskins received the ascites in KGM without saponin. After a 24 -h incubation at $37^{\circ} \mathrm{C}$ in a $5 \% \mathrm{CO}_{2}$ incubator the tissue was frozen and cryosectioned. Sections of test and control skin were stained with FITC-conjugated goat anti-mouse IgM and examined with a Nikon fluorescent microscope.

Immunolocalization of epitopes by immunoelectronmicroscopy. Tissue sections of normal adult breast skin were fixed in $4 \%$ paraformaldehyde in phosphate buffer for $4 \mathrm{~h}$ at room temperature. The tissue was then embedded at low temperature and polymerized at $-20^{\circ} \mathrm{C}$ with ultraviolet light using Lowicryl K4M (Polysciences, Inc., Warrington, PA). Thin sections on nickel grids were immunostained with ROC
129.1 ascites $(1: 1,000)$ at $4^{\circ} \mathrm{C}$ overnight. After washing the grids with PBS a secondary gold labeled goat anti-mouse IgM (Janssen Laboratories, Piscataway, NJ) was applied to the grids for $30 \mathrm{~min}$ at room temperature. After rinsing with PBS the grids were stained with uranyl acetate and lead citrate and examined with a Hitachi HS-8 electron microscope.

Characterization of epidermal fractions reacting with the monoclonal antibody. A cell envelope fraction was prepared according to the method of Labib et al. (18). Briefly, skin was obtained from reduction mammoplasties, heat separated at $56^{\circ} \mathrm{C}$ for $45 \mathrm{~s}$, and then placed on ice. The epidermis was serially extracted in $20 \mathrm{mM}$ TBS, pH 7.6, $1 \%$ nonidet $\mathrm{P}-40$, and $1.5 \mathrm{M} \mathrm{KCl} .10 \mu \mathrm{l}$ of each sample was tested by dot blotting with ROC 129.1. The remaining insoluble pellet digested with $0.04 \mathrm{mg} / \mathrm{ml}$ trypsin for $2 \mathrm{~h}$ at room temperature. Trypsinization was stopped by adding $5 \mathrm{mM}$ PMSF and the digest was again spun at $10,000 \mathrm{~g}$ for $10 \mathrm{~min}$. The trypsin-resistant pellet was suspended in TBS and washed before using it for further studies. $1 \%$ SDS extracts of the trypsin-resistant pellet revealed no bands by SDS-PAGE with Coomassie blue staining, and did not react with ROC 129.1 by immunoblotting.

The trypsin-resistant pellet was embedded in OCT compound (Miles, Elkhart, IN), frozen in liquid nitrogen, and sectioned in a cryostat. The sections were tested for the reactivity with ROC 129.1 using the same protocol as previously described.

Immunoadsorption of the monoclonal antibody with the cell envelope fraction. The trypsin-resistant pellet was also tested for its ability to immunoadsorb the ROC 129.1 antibody. An equal volume of the pellet was mixed with ROC 129.1 ascites $1: 5,000$ and incubated for 30 $\mathrm{min}$. The mixture was centrifuged at $10,000 \mathrm{~g}$ for $10 \mathrm{~min}$. The supernatant was tested for residual ROC 129.1 antibody reactivity by indirect IF on cryosections and Western blotting against epidermal proteins separated by SDS-PAGE. After immunoadsorbing ROC 129.1 antibody the pellet was tested by direct IF with an FITC-conjugated antiIgM. A control bullous pemphigoid serum containing antibodies against the cutaneous basement membrane zone was similarly adsorbed with the cell envelope-associated pellet.

\section{Results}

Human epidermal extract contains calmodulin-binding proteins. Using blotting procedures biotinylated calmodulin identified 10 bands from the Tris-SDS extract from whole epidermis. These bands ranged in $M_{\mathrm{r}}$ between 80 and $260 \mathrm{kD}$. Seven polypeptides show an $M_{\mathrm{r}}$ between 120-260 kD. Three bands

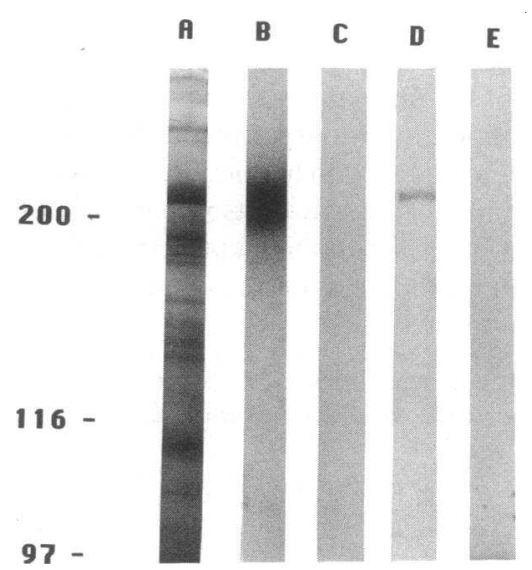

Figure 1. Western blotting of a total human epidermal extract with ROC 129.1 and bioCaM. Lane $A$ shows Coomassie blue staining of the epidermal extract. Nitrocellulose strips were reacted with ROC 129.1, 1:1,000 or $10 \mu \mathrm{g} / \mathrm{ml}$ of bio-CaM. Both ROC 129.1 (lane $B$ ) and bio-CaM (lane D) recognized a $250-\mathrm{kD}$ peptide band. Lane $C$ is a control strip reacted with secondary anti-

body alone. The presence of $5 \mathrm{mM}$ EGTA during incubation with bio-CaM abolished the reactivity with the $250-\mathrm{kD}$ band (lane $E$ ). 


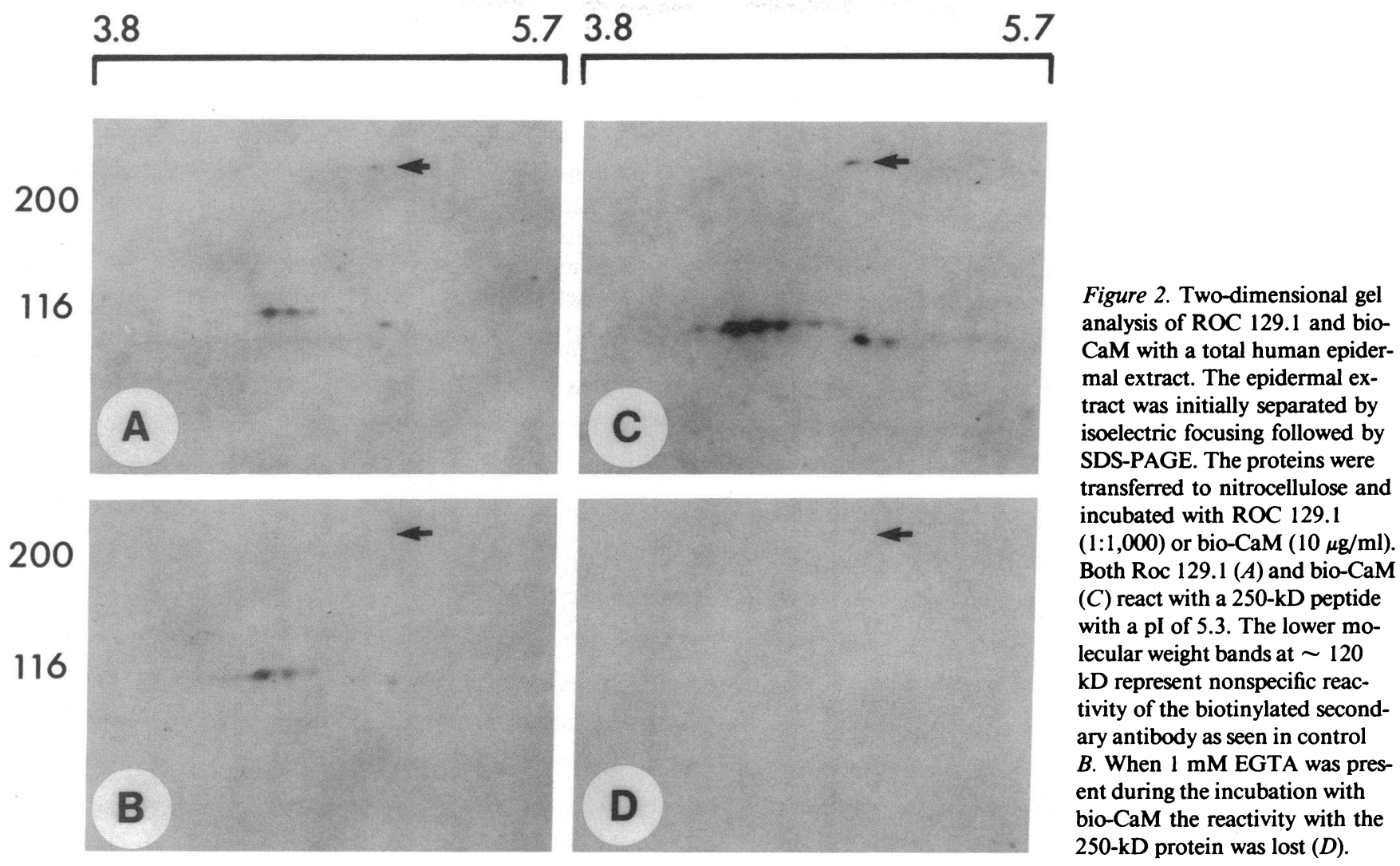

which were consistently weaker had an $M_{\mathrm{r}}$ below $160 \mathrm{kD}$. After affinity purification on the calmodulin affinity column two bands were visible by Coomassie staining at 250 and $160 \mathrm{kD}$. Using these column purified calmodulin-binding proteins as immunogens four hybridomas were generated. One of the hybridoma-produced IgM monoclonal antibodies named ROC 129.1 was further characterized.
The ROC 129.1 monoclonal antibody recognizes a high molecular weight epidermal calmodulin-binding protein. As shown in Fig. 1 the ROC 129.1 monoclonal antibody bound a 250-kD polypeptide by immunoblotting procedures. By twodimensional gel analysis the $250-\mathrm{kD}$ band had a pI of 5.3 (Fig. 2). Bio-CaM reacted with a band of the same molecular weight, and the EGTA control demonstrated the calcium dependency

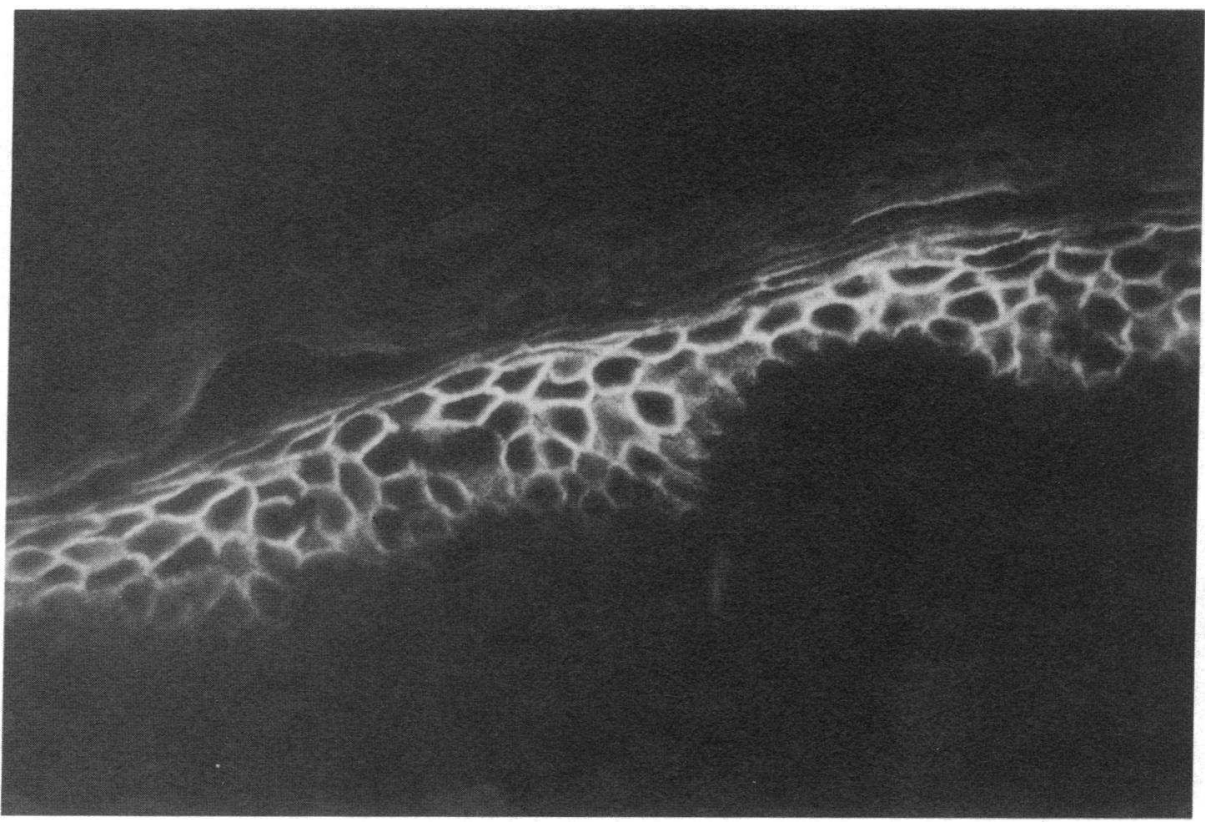

Figure 3. Indirect immunofluorescent staining with ROC $129.1(1: 1,000)$ and fluorescein conjugated anti-mouse IgM on cryosections of adult human skin. Staining is seen at the periphery of the keratinocytes but spares the BMZ. The titer of the ascites was $1: 40,000$ by indirect IF on human skin. 


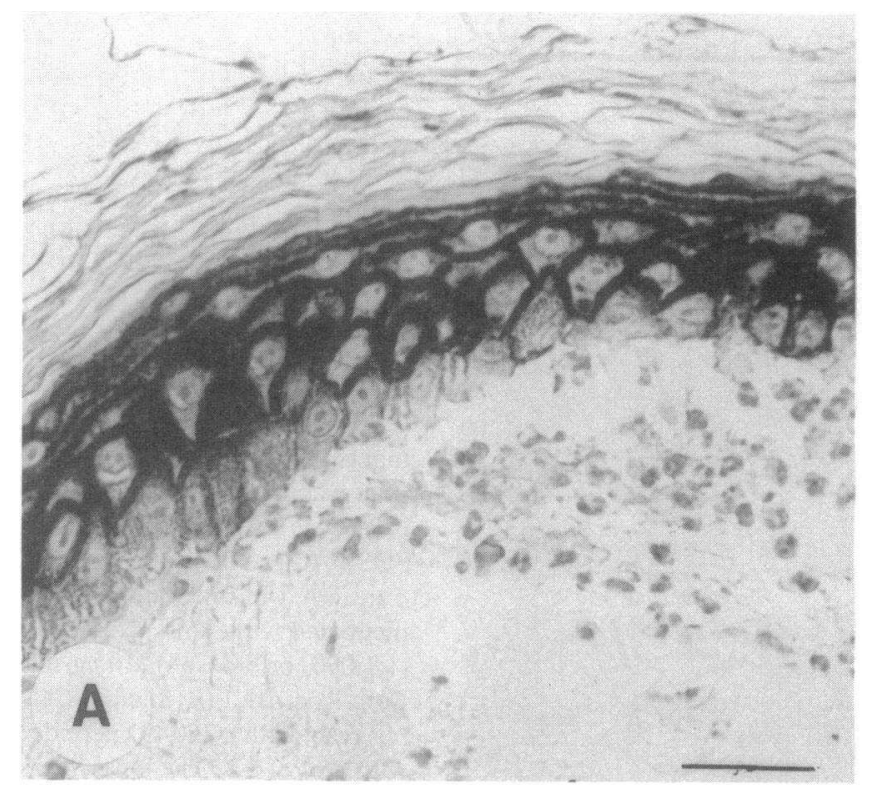

of the reactivity. A band of $160 \mathrm{kD}$ was detected occasionally in the Western blots with ROC 129.1.

ROC 129.1 exhibited no reactivity with human spectrin, calmodulin, or with any component of a bovine desmosome preparation. Bio-CaM, however, reacted with a $240-\mathrm{kD}$ bovine desmosomal protein (data not shown).

Developmental and tissue specificity of the ROC 129.1 monoclonal antibody by indirect IF and immunocytochemistry. IF staining of adult human skin demonstrated that ROC 129.1 reacted with a keratinocyte antigen located at the cell periphery (Fig. 3). As seen in this figure, no staining was seen in the area of the basement membrane zone (BMZ). The keratinocytes of the outer root sheath of the hair follicles showed a similar staining pattern as did eccrine ducts. The staining pattern of neonatal foreskin was identical to adult skin as was that from 12-, 14-, and 16-wk fetuses. However, the skin from the scalp, shoulder, and trunk of fetuses of $8 \mathrm{wk}$ of age did not bind the ROC 129.1 (data not shown).

Immunocytochemical staining of human epidermis with ROC 129.1 revealed a pattern identical to that obtained by indirect IF. Squamous mucosal surfaces including vulva, vagina, cervix, oral mucosa, and esophagus showed no staining. A survey of prostate, endometrium, cardiac muscle, duodenum, colon, small bowel, and stomach were also negative.

Species specificity of ROC 129.1 monoclonal antibody by indirect $I F$. Neither bovine tongue nor neonatal mouse epidermis showed any reactivity with ROC 129.1 by indirect IF techniques. Monkey skin, however, showed a pattern identical to human skin.

The reactivity of the ROC 129.1 monoclonal antibody is altered in acantholytic diseases. The lesional epidermis of four cases of pemphigus foliaceus tested showed a similar staining pattern with ROC 129.1, consisting of partial to complete absence of staining in the keratinocytes below the area of epidermal separation (Fig. $4 C$ ). Nonblistered epidermis surrounding the subcorneal vesicles maintained the same staining pattern as normal epidermis. The two cases of pemphigus vulgaris and one bullous pemphigoid all showed staining patterns similar to normal epidermis even in involved areas (Fig. 4, $A$ and $B$ ).

The ROC 129.1 monoclonal antibody identifies an intracellular desmosome-associated epitope. In organ culture, epidermis, which had been permeabilized with $0.1 \%$ saponin and incubated with ROC 129.1, showed the same staining pattern described on cryosections of human epidermis (Fig. $5 A$ ). In contrast, nonpermeabilized epidermis showed no staining with ROC 129.1 (Fig. 5 B).

Immunogold techniques showed immunoreactants located on the desmosomal plaque near the insertion of the intermediate filaments (Fig. 6) into epidermal desmosomes. Intermediate filaments not associated with the desmosomes did not bind the ROC 129.1 monoclonal antibody.

Figure 4. ROC 129.1 staining in bullous skin disorders. 5- $\mu \mathrm{m}$ sections were cut from formalin fixed paraffin embedded biopsy tissue. The sections were incubated for 30 min with ROC 129.1 (1:100) followed by a biotinylated secondary antibody and an avidin-biotin-peroxidase complex. The staining pattern in bullous pemphigoid $(A)$ and pemphigus vulgaris $(B)$ was the same as in normal skin. In contrast, pemphigus foliaceus shows almost complete loss of staining in the epidermis beneath the blister cavity $(C)$. The inset shows a closeup of the base of the blister cavity in PF. Bar $=2.5 \mu$. 

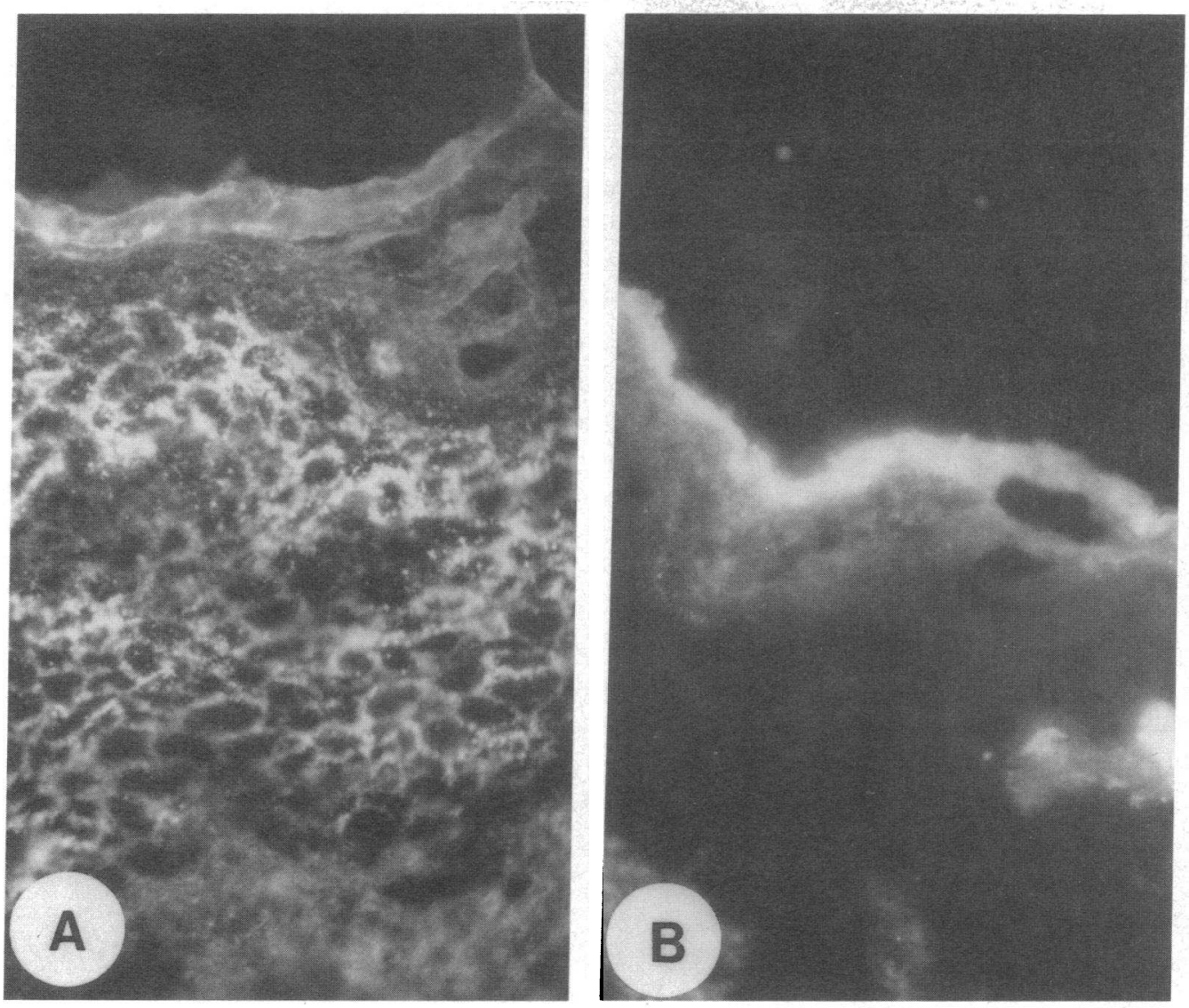

Figure 5. Comparison of staining with ROC 129.1 in permeabilized and nonpermeabilized human epidermis in organ culture. Skin was incubated for $24 \mathrm{~h}$ with ROC 129.1 1:100 in the presence of $0.1 \%$ saponin for permeabilization; control cultures were incubated with ROC 129.1 alone. The skin was removed from culture, cryosectioned, and incubated with FITC-conjugated anti-mouse IgM. Organ cultures, which were permeabilized with saponin, showed staining of the keratinocyte periphery identical to that seen on cryosections of human skin by indirect IF $(A)$. Epidermis incubated without saponin permeabilization showed no staining by direct IF $(B)$.

The epitope recognized by the ROC 129.1 monoclonal antibody is linked to the cell-envelope fraction. The cell envelope fraction showed strong reactivity with ROC 129.1 antibody. In

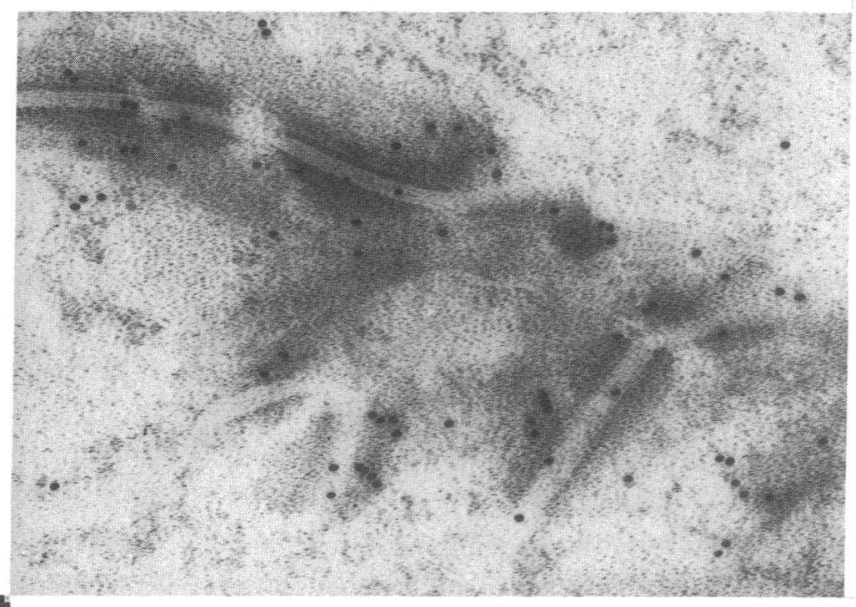

Figure 6. Immunoelectronmicroscopy with ROC 129.1 and gold labeled anti-mouse IgM on human epidermis. Normal adult skin was fixed in $4 \%$ paraformaldehyde, low temperature embedded, and thin sectioned. The sections were stained with ROC $129.1(1: 1,000)$ followed by gold labeled anti-mouse IgM. Gold particles localized ROC 129.1 reactivity to the plaque of epidermal desmosomes. Magnification, 64,000 . addition, the pellet could adsorb out the ability of the monoclonal antibody to label the epidermis by indirect IF (Fig. $7 A$ and $B)$. The pellet used to immunoadsorb the ROC 129.1 reacted strongly by direct IF with FITC-conjugated anti-mouse IgM, indicating the pellet had adsorbed rather than destroyed the antibody. The pellet was also able to abolish the reactivity of ROC 129.1 with the $250-\mathrm{kD}$ polypeptide by Western blotting (Fig. 7 D). A similar pellet was unable to adsorb bullous pemphigoid autoantibodies from a serum used as a control.

\section{Discussion}

Epidermal desmosome assembly is regulated by extracellular calcium in vitro. Under low calcium conditions (0.01-0.09 $\mathrm{mM}$ ) desmosomes fail to form, while switching the keratinocytes to high calcium ( $>0.1 \mathrm{mM}$ ) will trigger desmosome assembly. During this calcium-induced assembly of desmosomes there is a redistribution of desmosome components. The desmoplakins and keratin filaments that have a perinuclear distribution under low calcium conditions move to the lateral margins of the cell surface in high calcium (19-21). The desmocollins are distributed over the entire cell surface in low calcium and move to the lateral cell margins with the calcium switch (20). Desmosome assembly is not affected by actinomycin D or cyclohexamide, indicating new synthesis of desmosome components is not needed (2). Initially the desmosomes are asymmetric; over a period of 2-5 h they become fully formed and symmetric (2). 

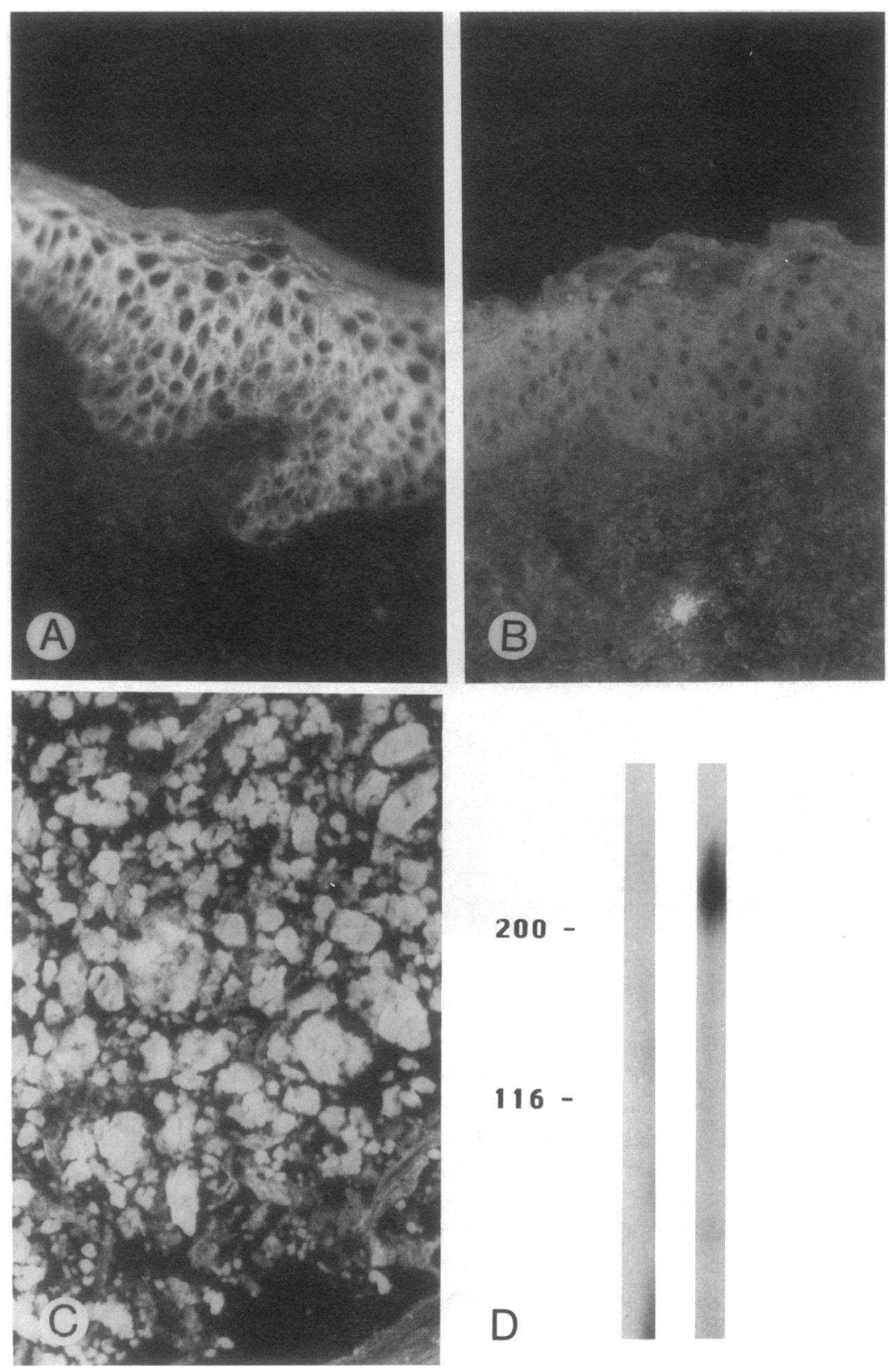

Figure 7. Identification of a cell envelope-associated pool of keratocalmin. A cell envelope pellet was prepared by serial extraction of human epidermis with 20 $\mathrm{mM}$ TBS, $1 \%$ nonidet $\mathrm{P}-40$, and $1.5 \mathrm{M} \mathrm{KCl}$. The remaining insoluble pellet was digested with $0.04 \mathrm{mg} / \mathrm{ml}$ trypsin for $2 \mathrm{~h}$. The pellet was washed and used in immunoadsorbtion studies with ROC 129.1 ascites. The staining pattern of ROC 129.1 on cryosections of human skin $(A)$ is abolished by preincubating the ascites with the trypsin-resistant cell envelope pellet $(B)$. The pellet used to adsorb the ascites showed strong reactivity by direct IF with anti-mouse IgM, indicating the pellet had adsorbed rather than destroyed the antibody activity. The pellet also adsorbed out the ability of the ascites to react with the 250-kD protein by Western blotting (shown in $D$ on the left) compared with the unadsorbed ascites on the right.

Calcium induction of desmosome assembly may occur through the direct interaction of calcium with desmosome components, or indirectly through calcium's effects on other regulatory proteins. Desmoglein I $(160 \mathrm{kD})$ and desmocollins I and II $(115,100 \mathrm{kD})$, have been shown to bind calcium using $\mathrm{a}^{45} \mathrm{Ca}^{++}$ overlay technique $(22,23)$. It is thought that calcium may interact directly with the extracellular portion of these transmembrane glycoproteins during desmosome assembly.

The role of the calcium regulatory protein, calmodulin, in desmosome formation is not clear. Low doses of the calmodulin inhibitor, W-7, which inhibits calmodulin kinase, do not prevent desmosome assembly in keratinocytes in vitro. However, higher doses of this calmodulin inhibitor, which will cause a more general inhibition of calmodulin-dependent proteins, will partially inhibit desmosome formation (24). In con- trast, calmodulin has been shown to be important in the formation of hemidesmosomes of corneal epithelium in vitro (11). The presence of a calmodulin-binding protein in bovine (25) and, as shown in this study, human desmosomes suggests further studies are needed to elucidate the role of calmodulin in desmosome physiology.

In this study we have demonstrated the presence of a human desmosomal protein that binds calmodulin in a calciumdependent manner. A calmodulin-binding protein termed desmocalmin has been previously described in bovine muzzle desmosomes (25). It is possible that our protein may be the human homologue of desmocalmin, as it shares certain similarities in molecular weight and pI ( 250 and 5.3 compared with 240 and $5.5 \mathrm{kD}$ reported for bovine desmocalmin). The epitopes that are recognized by ROC 129.1 , however, are specific to primate 
epidermal keratinocytes and not to bovine tissue because ROC 129.1 did not react with bovine tongue epithelium or a bovine desmosome preparation from muzzle. Tsukita and Tsukita have shown that desmocalmin coprecipitates with keratin filaments in vitro, and hypothesized that its function might be in integration of intermediate filaments into the desmosomal plaque (25). As the 129.1 antigen colocalized with the insertion site of the keratin filaments into the desmosome, it is possible the two may exhibit similar biologic properties. The $250-\mathrm{kD}$ polypeptide recognized by ROC 129.1 has been named keratocalmin, because of its restriction to epidermal keratinocytes and its calmodulin binding properties, until its relationship to desmocalmin can be determined.

Keratocalmin has an $M_{\mathrm{r}}$ similar to that of desmoplakin I $(240 \mathrm{kD})$, however desmoplakin I has a neutral pI as compared with 5.3 for keratocalmin (26). In addition, desmoplakin has a much wider tissue distribution than is apparent for keratocalmin (27). Recently the sequence of desmoplakin I/II has been reported (28). As sequences are determined for the various desmosomal components, the exact relationship between keratocalmin and the other desmosomal components will become apparent.

Two pools of keratocalmin have been identified in human epidermis: the soluble pool, which was extracted initially in Tris buffer during preparation of the partially purified calmodulin-binding proteins, and the insoluble cell envelope-associated pool. The cell envelope fraction has previously been shown to contain desmosomal remnants by electron microscopy (18). Based on preliminary extraction experiments of keratocalmin from human epidermis the insoluble pool may represent the major fraction of this protein. When desmosome assembly is induced by calcium in vitro, a further stabilization occurs which prevents disassembly by calcium chelating agents (23). As both keratocalmin and desmoglein I are contained in an insoluble envelope-associated pool, this stabilization may involve cross-linking of some desmosomal components to the cell envelope (18).

Though a pool of keratocalmin has been shown to be associated with the cell envelope fraction no staining of the stratum corneum was seen by immunofluorescent or immunohistochemical techniques. The failure of stratum corneum staining in likely due to lack of access of the antibody to the antigen within the highly cross-linked cell envelope. The envelope fraction is prepared by extensive extraction of the epidermis in $\mathrm{NP}-40, \mathrm{KCl}$, and then followed by trypsinization; this fraction was demonstrated to clearly absorb out the antibody reactivity from the ascites. These extraction conditions may expose antigenic sites not normally exposed by sectioning skin.

Desmosome components are the target of autoantibody formation in the blistering disorder pemphigus foliaceus (PF). In PF the patients develop antibodies against the transmembrane desmosomal glycoprotein, desmoglein I (29-31). The pathogenicity of the autoantibodies has been demonstrated by the ability of the human antibodies to induce blistering by passive transfer in neonatal mice (32). The loss of reactivity of 129.1 staining within the blistering lesion of PF may indicate that keratocalmin is located near desmoglein I. The loss of staining is not likely to be due to autoantibody blocking because the staining of ROC 129.1 is preserved in perilesional skin, an area in which PF antibodies are bound (33). Destruction of desmosomal components by the ensuing inflammatory events after PF antibodies are bound may explain the augmentation of blister formation by complement and proteases found in some experimental systems (34-38) and the loss of ROC 129.1 reactivity in the base of the lesions.

These studies do not directly address the function of keratocalmin. However, its localization to the desmosome and destruction in PF warrant further investigation into its possible role in cell adhesion. In addition, keratocalmin arises between 8-12 wk of gestational age, the stage when fetal skin begins to stratify. This is similar to the appearance of other cell surface proteins which have importance in cell-cell attachment such as the pemphigus vulgaris antigen (39). Because calmodulin and its binding proteins act to modulate cell function in a calciumdependent manner, we plan to further study the effects of this protein on calcium-dependent desmosome assembly.

\section{References}

1. Hennings, H., D. Michael, C. Cheng, P. Steinert, K. Holbrook, and S. Yuspa. 1980. Calcium regulation of growth and differentiation of mouse epidermal cells in culture. Cell. 19:245-254.

2. Hennings, H., and K. Holbrook. 1983. Calcium regulation of cell-cell contact and differentiation of epidermal cells in culture. Exp. Cell Res. 143:127-142.

3. Boyce, S. T., and R. G. Ham. 1983. Calcium-regulated differentiation of normal human epidermal keratinocytes in chemically defined clonal culture and serum-free serial culture. J. Invest. Dermatol. 81:33s-40s.

4. Ziboh, V. A., R. R. Isseroff, and R. Pandey. 1984. Phospholipid metabolism in calcium-regulated differentiation in cultures murine keratinocytes. Biochem. Biophys. Res. Commun. 122:1234-1240.

5. Jaken, S., and S. Yuspa. 1988. Early signals for keratinocyte differentiation: role of $\mathrm{Ca}^{2+}$-mediated inositol lipid metabolism in normal and neoplastic epidermal cells. Carcinogenesis. 9:1033-1038.

6. Tang, W., V. Ziboh, R. Isseroff, and D. Martinez. 1988. Turnover of inositol phospholipids in cultured murine keratinocytes: possible involvement of inositol triphosphate in cellular differentiation. J. Invest. Dermatol. 90:37-43.

7. Hennings, H., P. Steinert, and M. M. Buxman. 1981. Calcium induction of transglutaminase and the formation of epsilon (gamma-glutamyl) lysine crosslinks in cultured mouse epidermal cells. Biochem. Biophys. Res. Commun. 102:739-745.

8. Cheung, W. Y. 1982. Calmodulin: an overview. Fed. Proc. 41:2253-2257.

9. Means, A. R., and J. R. Dedman. 1980. Calmodulin-an intracellular calcium receptor. Nature (Lond.). 285:73-78.

10. Putkey, J. A., T. Ono, M. F. A. VanBerkum, and A. Means. 1988. Functional significance of the central helix in calmodulin. J. Biol. Chem. 263:1124211249.

11. Trinkaus-Randall, V., and I. K. Gipson. 1984. Role of calcium and calmodulin in hemidesmosome formation in vitro. J. Cell Biol. 98:1565-1571.

12. Wallace, R. W. T. J. Lynch, A. E. Tallant, and W. Y. Cheung. 1979. Purification and characterization of an inhibitor protein of brain adenylate cyclase and cyclic nucleotide phosphodiesterase. J. Biol. Chem. 254:377-382.

13. Billingsley, M. L., K. R. Pennypacker, C. G. Hoover, D. J. Brigati, and R. L. Kincaid. 1985. A rapid method for detection and quantification of calcineurin and calmodulin-binding proteins using biotinylated calmodulin. Proc. Natl. Acad. Sci. USA. 82:7585-7589.

14. Kohler, G., and C. Milstein. 1975. Continuous cultures of fused cells secreting antibody of predefined sensitivity. Nature (Lond.). 256:495-497.

15. Laemmli, U. K. 1970 . Cleavage of structural proteins during the assembly of the head of bacteriophage T4. Nature (Lond.). 227:680-685.

16. Towbin, H., T. Staehelin, and J. Gordon. 1979. Electrophoretic transfer of proteins from polyacrylamide gels to nitrocellulose sheets; procedure and some applications. Proc. Natl. Acad. Sci. USA. 76:4350-4354.

17. O'Farrell, P. H. 1975. High resolution two-dimensional electrophoresis of proteins. J. Biol. Chem. 250:4007-4021.

18. Labib, R. S., S. Camargo, S. Futamura, C. R. Martins, B. Rock, G. A. Anhalt, and L. A. Diaz. 1989. Pemphigus foliaceus antigen: characterization of a keratinocyte envelope associated pool and preparation of a soluble immunoreactive fragment. J. Invest. Dermatol. 93:272-279.

19. Jones, J. C. R., A. E. Goldman, P. M. Steinert, S. Yuspa, and R. D. Goldman. 1982. The dynamic aspects of the supramolecular organization of the intermediate filament networks in cultured epidermal cells. Cell Motil. 2:196213.

20. Watt, F. M., D. L. Mattey, and D. R. Garrod. 1984. Calcium-induced 
reorganization of desmosomal components in cultured human keratinocytes. $J$. Cell Biol. 99:2211-2215.

21. Jones, J. C. R., and R. D. Goldman. 1985. Intermediate filaments and the initiation of desmosome assembly. J. Cell Biol. 101:506-517.

22. Steinberg, M. S., H. Shida, G. J. Giudice, M. Shida, N. Patel, and O. W. Blaschuk. 1987. On the molecular organization, diversity and functions of desmosomal proteins. In Ciba Foundation Symposia 125: Junctional Complexes of Epithelial Cells. G. Bock, editor. John Wiley and Sons, New York. 3-25.

23. Mattey, D. L., A. Suhrbier, E. Parrish, and D. R. Garrod. 1987. Recognition, calcium and the control of desmosome formation. In Ciba Foundation Symposia 125: Junctional Complexes of Epithelial Cells. G. Bock, editor. John Wiley and Sons, New York. 49-65.

24. Sheu, H. M., Y. Kitajima, and H. Yaoita. 1989. Involvement of protein kinase $\mathrm{C}$ in translocation of desmoplakins from cytosol to plasma membrane during desmosome formation in human squamous cell carcinoma cells grown in low to normal calcium concentration. Exp. Cell Res. 185:176-190.

25. Tsukita, S., and S. Tsukita. 1985. Desmocalmin: a calmodulin-binding high molecular weight protein isolated from desmosomes. J. Cell Biol. 101:20702080.

26. Mueller, H., and W. W. Franke. 1983. Biochemical and immunological characterization of desmoplakins I and II, the major polypeptides of the desmosomal plaque. J. Mol. Biol. 163:647-671.

27. Cowin, P., and D. R. Garrod. 1983. Antibodies to epithelial desmosomes show a wide tissue and species cross-reactivity. Nature (Lond.). 302:148-150.

28. Green, K. J., D. A. D. Parry, P. M. Steinert, M. L. A. Virata, R. M. Wagner, B. D. Angst, and L. A. Nilles. 1990. Structure of human desmoplakins, implications for function in the desmosomal plaque. J. Biol. Chem. 265:26032612.

29. Koulu, L., A. Kusumi, M. S. Steinberg, V. Klaus-Kovtun, and J. R. Stanley. 1984. Human autoantibodies against a desmosomal core protein in pemphigus foliaceus. J. Exp. Med. 160:1509-1518.
30. Stanley, J. R., L. Koulu, V. Klaus-Kovtun, and M. S. Steinberg. 1986. A monoclonal antibody to the desmosomal glycoprotein desmoglein I binds the same polypeptide as human autoantibodies in pemphigus foliaceus. J. Immunol. 13336:1227-1230

31. Eyre, R. W., and J. R. Stanley. 1987. Human autoantibodies against a desmosomal protein complex with a calcium sensitive epitope are characteristic of pemphigus foliaceus patients. J. Exp. Med. 165:1719-1724.

32. Roscoe, J. T., L. A. Diaz, S. A. Sampaio, R. M. Castro, R. S. Labib, Y. Takahashi, H. P. Patel, and G. J. Anhalt. 1985. Brazilian pemphigus foliaceus autoantibodies are pathogenic to $\mathrm{BALB} / \mathrm{c}$ mice by passive transfer. $J$. Invest. Dermatol. 85:538-541.

33. Beutner, E. H., L. A. Prigenzi, W. Hale, C. A. Leme, and O. G. Bier. 1968 Immunofluorescent studies of autoantibodies to intercellular areas of epithelia in Brazilian pemphigus foliaceus. Proc. Soc. Exp. Biol. Med. 127:81-86.

34. Farb, R. M., R. Dykes, and G. S. Lazarus. 1978. Anti-epidermal-cell-surface pemphigus antibody detaches viable epidermal cells from culture plates by activation of proteinase. Proc. Natl. Acad. Sci. USA. 75:459-463.

35. Schiltz, J. R., B. Michel, and R. Papay. 1978. Pemphigus antibody interaction with human epidermal cells in culture. J. Clin. Invest. 62:778-788.

36. Schiltz, J. R., B. Michel, and R. Papay. 1979. Appearance of "pemphigus acantholytic factor" in human skin cultured with pemphigus antibody. J. Invest. Dermatol. 73:575-581.

37. Kawana, S., W. D. Geoghegan, and R. E. Jordon. 1985. Complement fixation by pemphigus antibody. II. Complement enhances detachment of epidermal cells. Clin. Exp. Immunol. 61:517-525.

38. Kawana, S., W. D. Geoghegan, and R. E. Jordon. 1986. Complement fixation by pemphigus antibody. III. Altered epidermal cell membrane integrity mediated by pemphigus antibody and complement. J. Invest. Dermatol. 86:2933.

39. Lane, A. T., K. F. Helm, and L. A. Goldsmith. Identification of bullous pemphigoid, pemphigus, laminin and anchoring fibril antigens in human fetal skin. 1985. J. Invest. Dermatol. 84:27-30. 